\title{
MACRÓFITAS AQUÁTICAS ASSOCIADAS AO RIO JACUÍPE, FEIRA DE SANTANA, BAHIA
}

\section{$\underline{\text { Murilo Cordeiro Vasconcelos }}{ }^{1}$; Flavio França ${ }^{2}$; Efigênia de Melo $^{3}$; Marise Carvalho ${ }^{4}$ e Robson Santos ${ }^{5}$}

1. Estagiário/UEFS, Graduando em Agronomia, Universidade Estadual de Feira de Santana email: murilocordeiro18@gmail.com

2. Orientador, Departamento de Ciências Biológicas, Universidade Estadual de Feira de Santana, e-mail: franca.flavio@gmail.com

3. Participante do projeto Departamento de Ciências Biológicas, Universidade Estadual de Feira de Santana, e-mail: efidemelo@ hotmail.com

4. Participante do projeto, Departamento de Ciências Biológicas, Universidade Estadual de

Feira de Santana, e-mail: marisecarvalho.tec@gmail.com

5. Participante do projeto, Departamento de Ciências Biológicas, Universidade Estadual de Feira de Santana, e-mail: robssantos17@hotmail.com

PALAVRAS-CHAVE: Plantas Aquáticas, preservação de mananciais, vegetação ciliar.

\section{INTRODUÇÃO}

As macrófitas aquáticas são, de forma geral, plantas terrestres, que durante seu processo de evolução, adaptaram-se a ecossistemas aquáticos, apresentando características de vegetais terrestres e uma grande capacidade para adaptação em diferentes ambientes. Também se caracterizam por serem plantas que habitam desde brejos até ambientes verdadeiramente aquáticos. São de suma importância nos ecossistemas aquáticos, por fornecerem a base da cadeia alimentar de ambientes aquáticos. Além disso, atuam como liberadores de nutrientes, absorvendo os nutrientes do sedimento por suas raízes e liberando-os na água. Também apresentam uma alta capacidade filtradora e despoluidora dos mananciais, sendo de grande importância em rios e lagoas de uso humano (Pott, 2000).

O Rio Jacuípe é um rio brasileiro, genuinamente baiano, que compõe a bacia do Paraguaçu. Suas nascentes localizam-se no município de Morro do Chapéu, em uma altitude de $1011 \mathrm{~m}$, cruzando o semiárido ao norte da Chapada Diamantina. Chega no município de Antônio Cardoso, onde desemboca no Rio Paraguaçu, formando o lago da barragem de Pedra do Cavalo, e desaguando na Baía de Todos os Santos, na região metropolitana de Salvador (Fontes et al, 2010). Contudo em algumas cidades que percorrem o rio, como a cidade de São José do Jacuípe, a canalização dos esgotos para dentro do corpo d'água vem trazendo diversos impactos, comprometendo a qualidade da água, prejudicando o seu uso para a pecuária, a agricultura e em atividades domesticas (Gomes, 2013).

Portanto, o estudo das macrófitas aquáticas associadas ao Rio Jacuípe torna-se importantíssimo, pois elas, com sua incrível capacidade filtradora e despoluidora são capazes por si próprias, de melhorar a qualidade da água do rio, tornando-a mais potável. Outro aspecto importante a ser considerado é que o Rio Jacuípe desagua no Rio Paraguaçu consequentemente formando a barragem de Pedra de Cavalo, que abastece algumas cidades 
da região do recôncavo baiano como Salvador e Feira de Santana, a primeira e a segunda maior cidade da Bahia, respectivamente.

\section{METODOLOGIA}

Foram realizadas coletas mensais no Rio Jacuípe. O material foi colhido de acordo com os métodos usuais de amostragem de material botânico (Mori et al, 1989). O material coletado foi depositado no herbário da Universidade Estadual de Feira de Santana (HUEFS).

O material coletado foi identificado utilizando a literatura especializada e através de comparação com materiais identificados por especialistas, depositado no HUEFS. Também houve o apoio de especialistas que eventualmente estavam em visita ao herbário.

A pesquisa do material depositado em herbários foi feita através do Species link (2016). O material citado no sítio eletrônico foi investigado sobre a sua correta identificação e localização.

Os resultados obtidos foram comparados utilizando-se índice de similaridade de Jaccard (Mueller-Dombois e Ellemberg, 1974), utilizando-se o aplicativo Past.

\section{RESULTADOS E DISCUSSÃO}

Foram coletadas 94 espécies, sendo 18 in det, 4 indeterminadas e 72 identificadas. São ervas, arbustos, arvoretas, árvores e macrófitas aquáticas. Dentre as espécies, as famílias com maior riqueza foram: Fabaceae (16 espécies); Euphorbiaceae e Asteraceae (6 espécies cada uma); Poaceae e Malvaceae (5 espécies cada uma). Essas famílias juntas representam 17,67\% da cobertura vegetal do rio e de sua margem, sendo 8,43\% de espécies de Fabaceae; 4,33\% de Poaceae; 2,28\% de Malvaceae; 2,05\% de Euphorbiaceae; e 0,58\% de Asteraceae. Dentre as plantas coletadas 11 são macrófitas aquáticas, ou seja, representando $11,70 \%$ do total coletado, uma do gênero Nymphaea (Nymphaeaceae), outra do gênero Najas (Hydrocharitaceae) e uma do gênero Cyperus (Cyperaceae), além de outras anfíbias. Dentre as plantas aquáticas temos as seguintes formas biológicas: 1 submersa livre (Najas microcarpa), 1 flutuante fixa (Nymphaea ampla), 1 emergente (Cyperus articulatus) e 8 anfíbias: Tarenaya spinosa (Cleomaceae), Ammannia latifólia (Lythraceae), Cyperus surinamensis (Cyperaceae), Eleocharis geniculata (Cyperaceae), Bacopa monnieri e Stemodia marítima (ambas Plantaginaceae), Eclipta prostrata (Asteraceae) e Euploca procumbens (Boraginaceae). Essas espécies, como a Najas microcarpa, a Nymphaea ampla e a Cyperus articulatus tem grande importância com sua capacidade de aumento da potabilidade da água, segundo POTT, 2000. 


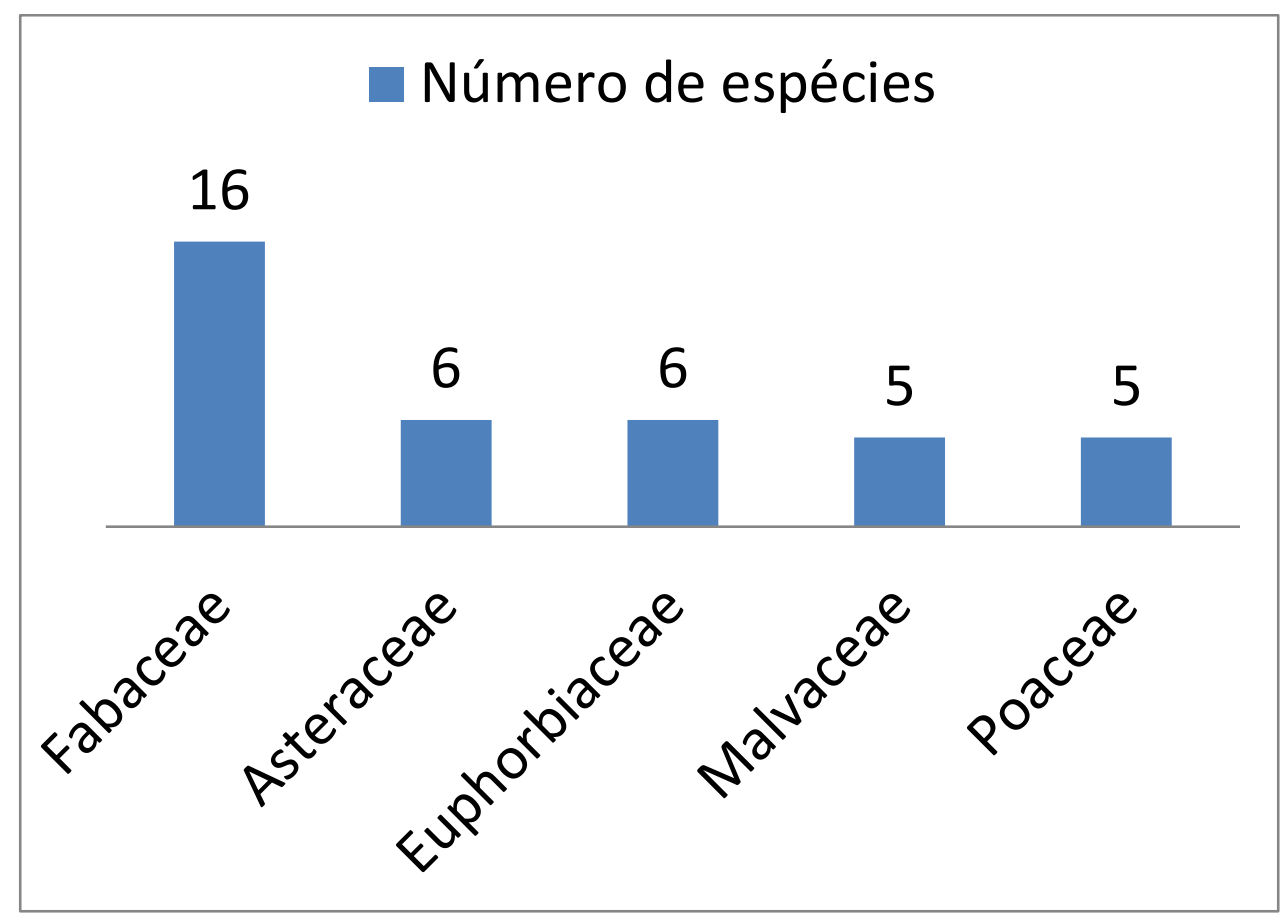

Gráfico 01: Famílias com as maiores ocorrências de espécies.

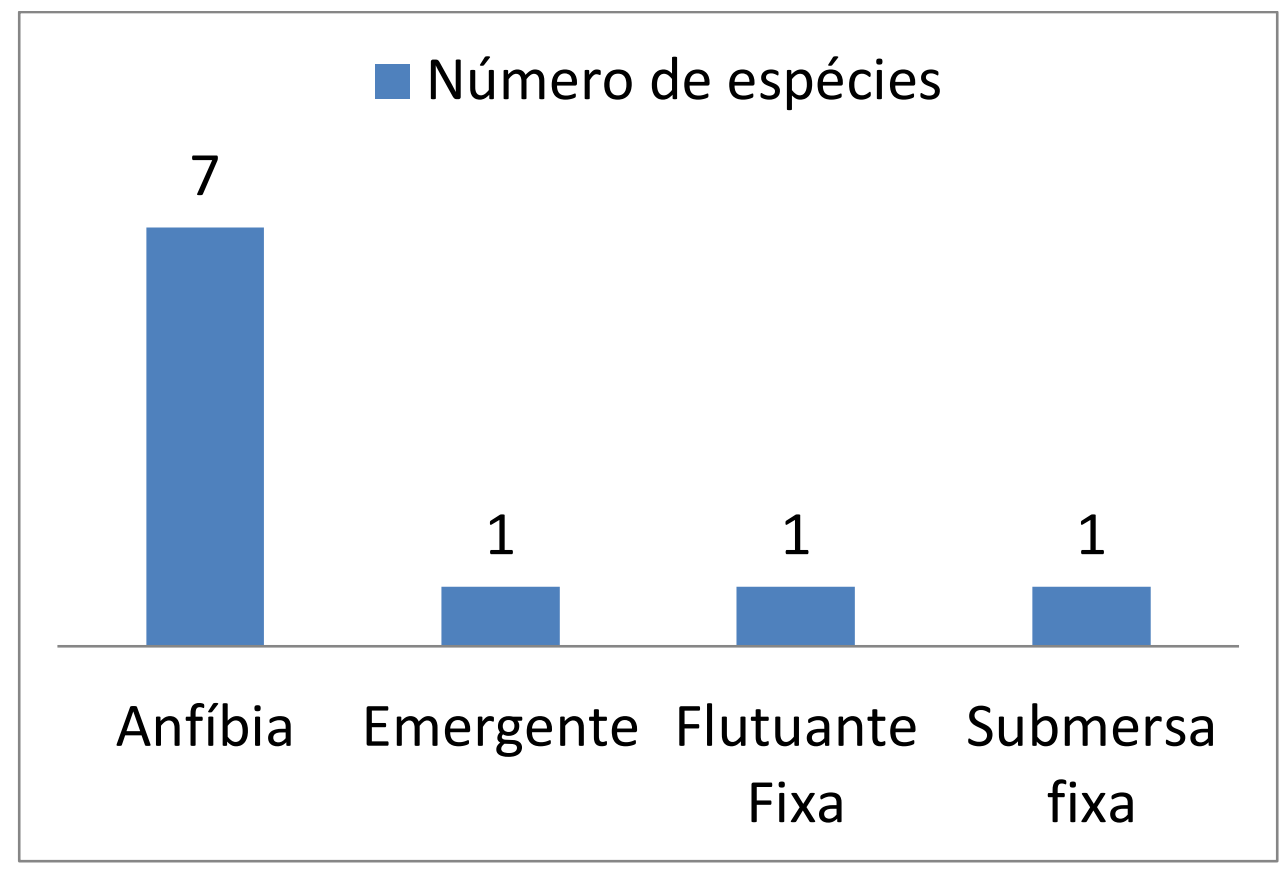

Gráfico 02: Formas biológicas das plantas aquáticas.

\section{CONSIDERAÇÕES FINAIS}

Observou-se que grande parte das espécies de macrófitas aquáticas coletadas são ervas anfíbias, em sua grande maioria nativas, sendo que esses foram encontrados em bancos de areia formados durante a época de enchentes e entre as rochas. Observou-se a escassez de macrófitas aquáticas, quando comparado ao trabalho de FRANÇA et al. (1999), onde encontrou-se 121 espécies encontradas em açudes próximos ao rio Jacuípe, comparado as 94 espécies coletadas deste trabalho. Neste trabalho as famílias Poaceae, Fabaceae e Asteraceae 
tiveram grande importância pelo número de espécies coletadas, concordando com o trabalho supracitado. Os dados anteriormente citados permite-se inferir que a diminuição da flora aquática no rio Jacuípe pode está relacionado com o intervalo de tempo (16 anos) entre os trabalhos, referindo-se ao aumento de ações antrópicas ocorridas no curso do rio nos últimos anos. Outra possível explicação para redução da flora aquática entre os trabalhos seria referente ao tipo de ecossistema dos ambientes de coleta, onde no objeto de estudo deste trabalho, o rio Jacuípe, é um ecossistema lótico, onde há movimentação da água, o que se supõe que haja o arrasto dessas macrófitas aquáticas no período de enchentes.

\section{REFERÊNCIAS}

FONTES, Andrea Souza, Calibração do Modelo Swat em Bacia do Semiárido com auxilio da hidrologia isotópica: X Simpósio de Recursos Hídricos do Nordeste - 2010.

FRANÇA et al. 2003. Flora vascular de açudes de uma região do semi-árido da Bahia, Brasil. Acta bot. Bras. 17(4):549-559. 2003.

GOMES, Phillipe. Queremos solução das autoridades competentes ao esgoto sanitário jogado no Rio Jacuípe, 2013. Disponível em :<

https://secure.avaaz.org/po/petition/Queremos_solucao_das_autoridades_competentes_ao_esg oto_sanitario_jogado_no_Rio_Jacuipe/?pv=4>. Acesso em 23/07/2016.

HAMMER,Ø., Harper, D.A.T., and P. D. Ryan, 2001. PAST: Paleontological Statistics SoftwarePackage for Education and Data Analysis. Palaeontologia Electronica 4(1):9pp.

MORI, S.A; Silva, L.A.M; Lisboa, G. \& CORADIN, L. 1989. Manual de Manejo do Herbário Fanerogâmico. 2 ed. Ilhéus: Centro de P esquisas do Cacau.

MUELLER-DOMBOIS, Dieter; ELLENBERG, Heinz - Aims and Methods of Vegetation Ecology; New York: John Willey \& Sons, 1974.

POTT, Vali Joana, Arnildo Pott. Plantas Aquáticas do Pantanal. Brasília : Embrapa Comunicação para Transferência de Tecnologia, 2000.

SIQUEIRA FILHO, J. A. A flora das caatingas do Rio São Francisco/ [organização]. I.ed. - Rio de Janeiro : Andrea Jakobsson, 2012.

Species Link, Dados e Ferramentas. Disponível em:< https://www.splink.cria.org.br >. Acesso em 20/10/2016. 